\title{
Vitamin D status in medical students and risk factor analysis
}

\author{
Vidya Sunil Joshi, Rahul Mandal \\ Department of Physiology, Vydehi Institute of Medical Sciences, \#82 EPIP area, Nallurahalli, Whitefield, \\ Bengaluru-560066, Karnataka, India.
}

\begin{tabular}{|c|c|}
\hline Article history & Abstract \\
\hline $\begin{array}{l}\text { Received } 31 \text { January } 2018 \\
\text { Revised } 11 \text { March } 2018 \\
\text { Accepted } 24 \text { March } 2018 \\
\text { Online } 30 \text { March } 2018 \\
\text { Print } 31 \text { March } 2018\end{array}$ & \multirow{3}{*}{ 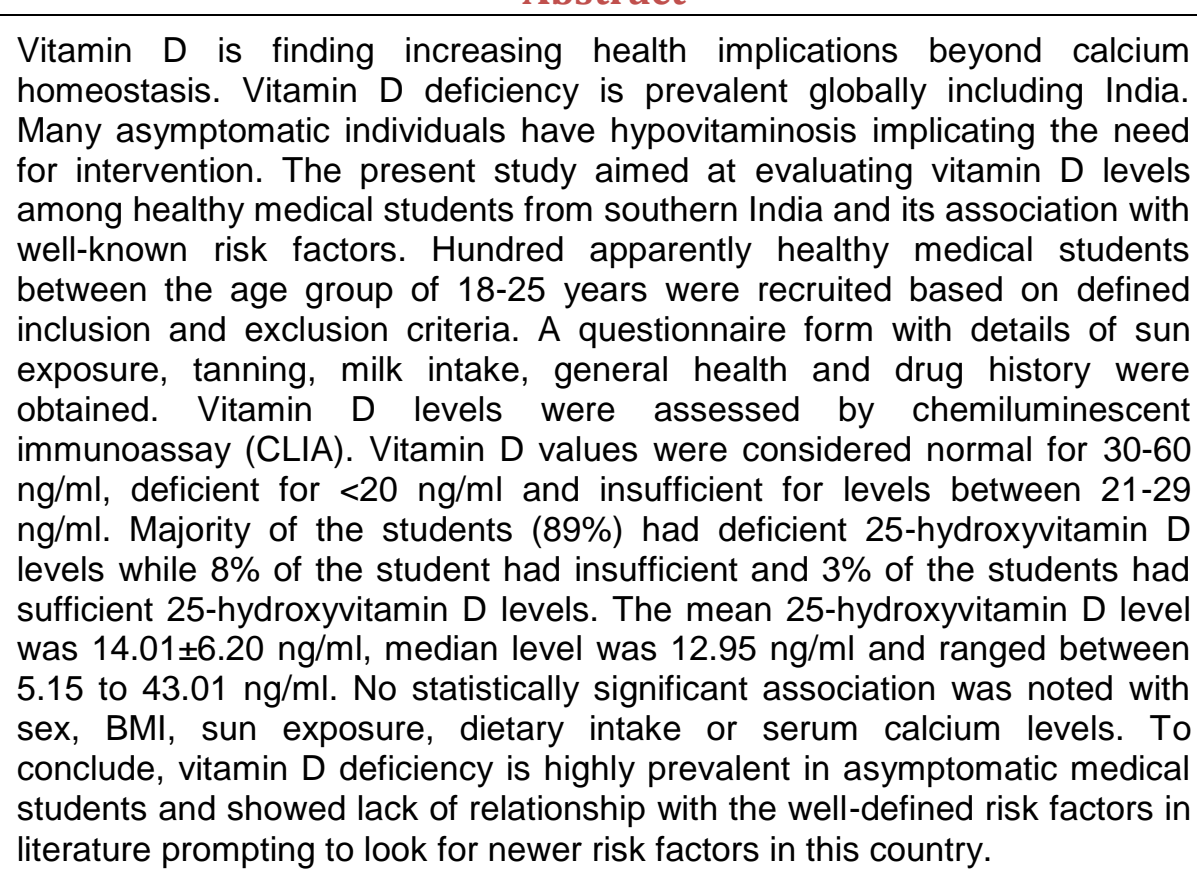 } \\
\hline Keywords & \\
\hline & \\
\hline
\end{tabular}

\section{Introduction}

Vitamin $D$ is increasingly being recognized as an important indicator of health [1]. It is involved in calcium homeostasis and skeletal health but identification of vitamin $\mathrm{D}$ receptors and its actions at cellular level have recognized its increasing role in health [2]. Vitamin D deficiency is commonly seen across the globe even in asymptomatic individuals [3]. Contrary to the belief it is common in sunny countries like India. Recent studies have

\footnotetext{
Corresponding author

Dr. Vidya Sunil Joshi

Associate Professor

Department of Physiology, Vydehi Institute of Medical Sciences,

\#82 EPIP area, Nallurahalli, Whitefield,

Bengaluru-560066, Karnataka, India.

Phone: +91-9379194110

Email: sunvidya99@gmail.com
}

indicated higher prevalence of vitamin D deficiency in health care workers. The primary aim of this study was to evaluate the prevalence of this condition among the group of medical students and identify risk factors associated with it.

\section{Materials and Methods}

This cross-sectional study was conducted in the Department of Physiology, Vydehi Institute of Medical Sciences, Bengaluru between September 
2015 and September 2017. Based on previous literature, considering $86 \%$ prevalence of vitamin D deficiency (average of result of i.e. $76 \%$ and $96 \%$ ) with $10 \%$ relative precision and $95 \%$ confidence level, the minimum required sample size was calculated as 63. As it was cross-sectional study, sample size was increased to recruit total of 100 apparently healthy medical students of either gender aged 18-25 years. Participants with history of liver disease, kidney disease, malabsorption syndrome, thyroid disease, hypertension and diabetes mellitus were excluded. Participants taking calcium and vitamin D supplements or drugs interfering with vitamin D metabolism were also excluded. Prior to the commencement, the ethical clearance was obtained from Institutional Ethics Committee. The medical students were screened for eligibility based on selection criteria. Those fulfilling selection criteria and expressing their willingness to participate in the study were explained about the nature of the study and these students were enrolled after obtaining a written informed consent. Medical students were interviewed and socio-demographic data like age, gender were noted and detailed history about liver disease, kidney disease, diabetes, supplementation of vitamin $\mathrm{D}$ and other medical history were obtained. Every student was provided with the questionnaire which covered various aspects pertaining to the dietary habits, exposure to sunlight, ethnic background, vitamin supplementation and evidence of malabsorption (Table 1) [4]. Further these students were subjected to clinical examination and blood pressure was noted so as to rule out hypertension. Following the clinical examination all the students underwent following investigations - Serum calcium and 25-hydroxyvitamin D estimation.

\section{Table 1: Questionnaire [4]}

\section{S. No. Question}

\begin{tabular}{lll}
\hline 1 & Have you received a suntan in the past 12 months? & Yes $\square$ No $\square$ \\
2 & Do you use sunscreen? & Yes $\square$ No $\square$ \\
3 & On average, how much sun exposure have you had in the past week? & 5-15 min/day $\square$ \\
& & $15-30$ min/day $\square$ \\
4 & Have you used a tanning booth in the past year? & 30 min/day $\square$ \\
5 & How many servings of milk do you get daily? & Yes $\square$ No $\square$ \\
6 & Do you take multivitamins? & 1 \\
& $\quad$ If yes, how many multivitamin tablets do you take daily? \\
7 & Do you take vitamin $D$ supplements or calcium with vitamin D? & Yes $\square$ No $\square$ \\
& $\quad$ If so, how many IU per day? & Yes $\square$ No $\square$ \\
8 & Do you take cod liver oil or omega-3 fatty acids (fish oil)? & Yes $\square$ No $\square$ \\
9 & What is your ethnic background? & Asian/African $\square$ \\
10 & Have you been diagnosed with crohn's disease, ulcerative colitis, or & American/Caucasian $\square$ \\
11 & Celiac sprue? & Yes $\square$ No $\square$ \\
\hline & Have you had diarrhea in the past 2 weeks? & Yes $\square$ No $\square$
\end{tabular}

About $2 \mathrm{ml}$ venous blood was collected from each participant. The blood was taken in BD Vacutainer and was kept sometime to allow for clot formation. Then it was centrifuged two times by REMI R-8M. Next the separated serum was collected in the Eppendorf tubes. Closed Eppendorf tubes were kept in refrigerating system maintaining temperature at $-20^{\circ} \mathrm{C}$. Before the tests, the serum samples were kept in room temperature and required amount was taken from those tubes.

Vitamin $D$ levels were assessed by chemiluminescent immunoassay (CLIA) method (VITROS eci, Johnson and Johnson Ortho Clinical
Diagnostics). The blood level of vitamin $\mathrm{D}$ was interpreted as follows:- Normal $30-60 \mathrm{ng} / \mathrm{ml}$, Deficient is $<20 \mathrm{ng} / \mathrm{ml}$ and Insufficient if vitamin levels between $21-29 \mathrm{ng} / \mathrm{ml}$.

\section{Statistical analysis}

The statistical analysis was done using SPSS version 20.0. The categorical variables were represented in terms of number and percentages. The continuous variables were reported as mean \pm standard deviation. The proportion of vitamin $D$ deficiency among the medical students was reported. The association between the categorical 
variables and hypovitaminosis $D$ was examined using Chi-Square test or Fisher's exact test as appropriate. The mean vitamin D levels among males and females were compared using independent sample t-test. A probability value ( $p$ values) of $<0.05$ was considered statistically significant.

\section{Results}

A total of 100 apparently healthy MBBS students aged between 18 and 25 years studying at Vydehi Institute of Medical Sciences \& Research Centre, Bengaluru were studied. In the present study, 54\% of the students were males and $46 \%$ were females. The male to female ratio was $1.17: 1$. 54\% of the students had history of use of sun tan in past 12 months and $51 \%$ of the students had 5 to 15 minutes duration of exposure to sun. Only one student $(1 \%)$ reported using tanning booth in past one year. In the present study, most of the students $(50 \%)$ had at least one milk serving per day. In this study $11 \%$ of the students reported history of multivitamin consumption, $9 \%$ had history of omega 3 fatty acids consumption and $5 \%$ of the students reported history of diarrhea. Body mass index (BMI) of most of the participants (44\%) was normal $\left(18.5\right.$ to $\left.22.99 \mathrm{~kg} / \mathrm{m}^{2}\right)$ while $10 \%$ of the students were underweight $\left(<18.5 \mathrm{~kg} / \mathrm{m}^{2}\right)$. The mean BMI levels were $22.34 \pm 3.23 \mathrm{~kg} / \mathrm{m}^{2}$ and median BMI was noted as $22.27 \mathrm{~kg} / \mathrm{m}^{2}$ with range 15.63 to $29.32 \mathrm{~kg} / \mathrm{m}^{2}$ (Table 2). Table 2: Demographic and test data of study participants

\begin{tabular}{lccccc} 
Variables & Mean & SD & Median & \multicolumn{2}{c}{ Range } \\
\cline { 5 - 6 } & & & & Minimum & Maximum \\
\hline Age (years) & 20.79 & 1.55 & 21.00 & 18.00 & 28.00 \\
No. of milk servings daily & 1.16 & 0.83 & 1.00 & 0.00 & 4.00 \\
Vitamin D $(\mathrm{ng} / \mathrm{ml})$ & 14.01 & 6.20 & 12.95 & 5.15 & 43.01 \\
Serum calcium $(\mathrm{mg} / \mathrm{dl})$ & 9.56 & 0.85 & 9.80 & 7.62 & 10.90 \\
Weight $(\mathrm{kg})$ & 63.00 & 12.84 & 62.00 & 40.00 & 95.00 \\
Height $(\mathrm{m})$ & 1.67 & 0.11 & 1.68 & 1.48 & 1.90 \\
Body mass index $\left(\mathrm{kg} / \mathrm{m}^{2}\right)$ & 22.34 & 3.23 & 22.27 & 15.63 & 29.32
\end{tabular}

In this study majority of the students (89\%) had deficient 25 -hydroxyvitamin $\mathrm{D}$ levels while $8 \%$ of the student had insufficient 25-hydroxyvitamin D levels and $3 \%$ of the students had sufficient 25 hydroxyvitamin D levels. The mean 25hydroxyvitamin D levels were $14.01 \pm 6.20 \mathrm{ng} / \mathrm{ml}$ and median levels were $12.95 \mathrm{ng} / \mathrm{ml}$ and ranged between 5.15 to $43.01 \mathrm{ng} / \mathrm{ml}$ (Table 2).

Sixty five percent of the students had serum calcium levels between 8.4 to $10.2 \mathrm{mg} / \mathrm{dl}$ while $22 \%$ had serum calcium levels of $>10.2 \mathrm{mg} / \mathrm{dl}$ and $13 \%$ had serum calcium levels of $<8.4 \mathrm{mg} / \mathrm{dl}$. The mean serum calcium levels were $9.56 \pm 0.85 \mathrm{mg} / \mathrm{dl}$ and median levels were $9.80 \mathrm{mg} / \mathrm{dl}$ with range 7.62 to $10.90 \mathrm{mg} / \mathrm{dl}$.

There was no association between sex and 25hydroxyvitamin $D$ levels $(p=0.597)$ in this study. The mean 25-hydroxyvitamin $D$ levels were slightly high in males $(15.17 \pm 5.06 \mathrm{ng} / \mathrm{ml})$ compared to females $(13.01 \pm 6.92 \mathrm{ng} / \mathrm{ml})$. But, the difference observed was statistically not significant $(p=0.084)$.

In this study the mean 25-hydroxyvitamin $D$ levels were low $(13.48 \pm 4.28 \mathrm{ng} / \mathrm{ml})$ in students with BMI between 25 to $29.99 \mathrm{~kg} / \mathrm{m}^{2}$, compared to those who had BMI between 23.00 to $24.99 \mathrm{~kg} / \mathrm{m}^{2}$ (13.70 $\pm 7.40 \mathrm{ng} / \mathrm{ml})$ and BMI between 18.5 to 22.99 $\mathrm{kg} / \mathrm{m}^{2}(14.55 \pm 46.71 \mathrm{ng} / \mathrm{ml})$. However the difference observed was statistically not significant $(p=0.896)$.

In the present study quantity of daily milk serving was not associated with 25-hydroxyvitamin D levels $(p=0.215)$. No association was found between duration of exposure to sun during last week with 25 -hydroxyvitamin D levels $(p=0.948)$ or use of sun tan in past 12 months with 25hydroxyvitamin $D$ levels $(p=0.597)$. Serum calcium levels showed no association with 25hydroxyvitamin D levels ( $p=0.962)$ (Table 2).

\section{Discussion}

Vitamin $D$ belongs to the group of fat-soluble vitamins. Diet is a poor source as very few foods contain vitamin $\mathrm{D}$; hence dermal synthesis is the major natural source of this vitamin. The dermal 7dehydrocholesterol gets converted in to pre-vitamin $D$ on absorbing UVB radiation from sunlight [5]. Vitamin $D$ from the diet or dermal synthesis is biologically inactive and requires enzymatic conversion to active metabolites (Figure 1). The central role of hormonal 1,25-dihydroxyvitamin D3 $\left[1,25(\mathrm{OH})_{2} \mathrm{D} 3\right]$ is to regulate calcium and phosphorus homeostasis via actions in intestine, kidney and bone [6]. 


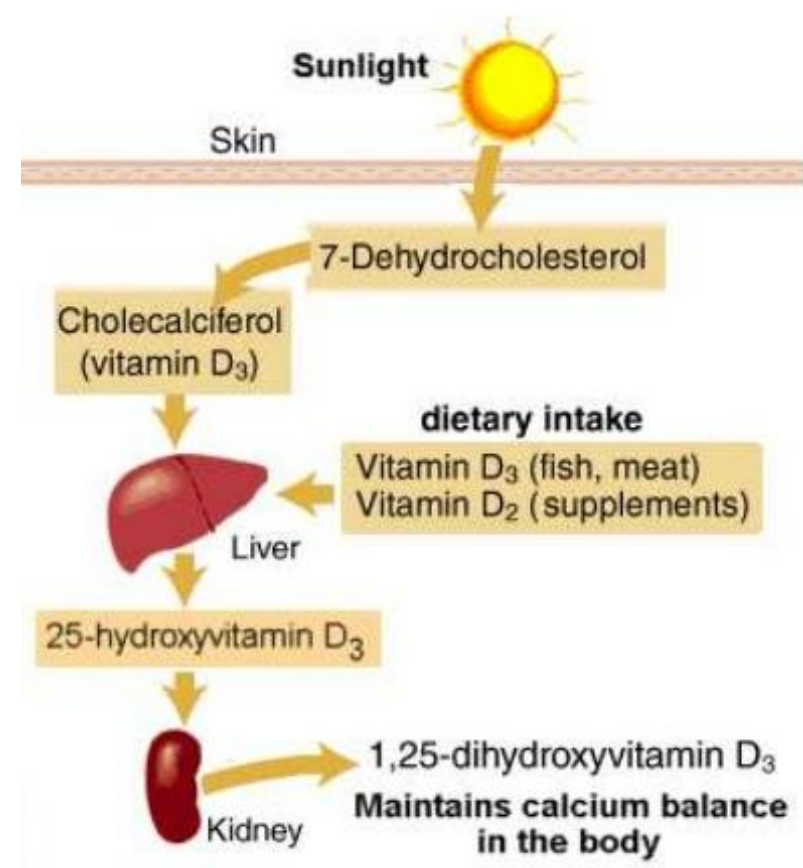

Figure 1. Biosynthesis of active form of vitamin $D$

These and other actions in many cell types not involved in mineral metabolism are mediated by the vitamin $D$ receptor. Its most important function is to enhance intestinal absorption of calcium. Other actions in the body are:- stimulation of intestinal phosphate absorption, suppression of parathyroid hormone (PTH) and regulation of osteoblast function. Vitamin $\mathrm{D}$ and its metabolites have a major role because of their interrelationship with calcium homeostasis and skeletal metabolism. Severe hypovitaminosis of vitamin $D$ resulting in Rickets (children) and osteomalacia (children and adults) is now uncommon except in high risk populations with unusually low sun exposure, lack of vitamin $D$ in fortified foods and malabsorptive syndromes. In addition to its vital role in calcium homeostasis, vitamin $D$ by the vitamin $D$ receptor (VDR) is involved in regulation of myocytes, cancer cells, and the immune, cardiovascular and metabolic system [2].

Vitamin $D$ deficiency occurs all over the world, mainly in the Middle East, China, Mongolia and India [7].Sub-clinical vitamin D deficiency, as measured by low serum $25(\mathrm{OH}) \mathrm{D}$, is very common. In the National Health and Nutrition Examination Survey (NHANES) 2005 to 2006, 41.6 per cent of adult participants ( $\geq 20$ years) had 25(OH)D levels below $20 \mathrm{ng} / \mathrm{ml}$ (50 nmol/L) [8].

Among different metabolites of vitamin $D$, values of $25(\mathrm{OH}) \mathrm{D}$ are more relevant than $1,25(\mathrm{OH}) 2 \mathrm{D}$ which has short half-life and does not decrease until severe deficiency. Although various methods of assessing vitamin D are available, the most cost effective and at the same time scientific and accurate test in serum is by chemiluminescent immunoassay (CLIA) technology [9]. It is a highly sensitive technology in which a specific antibody to vitamin $D$ is used for coating magnetic particles (solid phase) and vitamin D is linked to an isoluminol derivative. During incubation, 25hydroxyvitamin $D$ dissociates from its binding proteins and competes with labelled vitamin $D$ for binding sites on the antibody. After incubation, the unbound material is removed with a wash cycle. Subsequently, starter reagents are added and a flash chemiluminescent reaction is initiated. The light signal is measured by a photomultiplier as relative light units and is inversely proportional to the concentration of 25-hydroxyvitamin D present in the samples.

The interpretation of blood level of vitamin $\mathrm{D}$ are as follows:- Normal $30-60 \mathrm{ng} / \mathrm{ml}$, Deficient if $<20$ $\mathrm{ng} / \mathrm{ml}$, Insufficient if vitamin levels between 21-29 $\mathrm{ng} / \mathrm{ml}$ [10]. The Recommended Dietary Allowance (RDA) for vitamin D is 600 International Units (IU) daily for adults through age 70 years and for children 1 to 18 years of age [11].

Vitamin D insufficiency appears to be common among those who are old aged, inadequately exposed to sun, dark skinned, obese, on medications that interfere with the metabolism of vitamin, use of sunscreens, osteoporosis, malabsorption including inflammatory bowel disease and celiac disease. There are several causes of vitamin D deficiency, including decreased intake or absorption, reduced sun exposure, increased hepatic catabolism, decreased endogenous synthesis (via decreased 25-hydroxylation in the liver or 1-hydroxylation in the kidney) or end-organ resistance to vitamin D.

In a population-based sample of Asian adults, approximately $75 \%$ had sub-optimal $25(\mathrm{OH}) \mathrm{D}$ concentrations [12]. In Asia, there is a growing concern regarding the potential for vitamin D insufficiency and deficiency. Sub-optimal concentration of $25(\mathrm{OH}) \mathrm{D}$ including insufficiency and deficiency were associated with age $<65$ years, female gender, Malay and Indian ethnicities, higher education and income levels, obesity and higher $\mathrm{HbA1c}$ [12].

Historically, Indians obtained most of their vitamin D through adequate sun exposure; however, darker complexion and the changes which have accompanied India's modernization including increased hours spent working indoors and pollution limit sun exposure for many. Inadequate sun exposure results in reduced vitamin $D$ synthesis and ultimately poor vitamin D status if not compensated by dietary intake. Dietary vitamin $D$ intake is very low in India because of low consumption of vitamin $D$ rich foods, less availability of fortified food and low use of supplements [13]. Surprisingly, in spite of being a 
country of abundant sunshine, the prevalence of Vitamin D deficiency in India has been found to be nearly $70 \%-90 \%$ across all age groups [14]. Shift workers, healthcare workers and indoor workers are at high risk of developing vitamin D deficiency, which may reflect key lifestyle differences [15].

In a study from Iran, nearly all medical students had $25(\mathrm{OH}) \mathrm{D}$ level of $<30 \mathrm{ng} / \mathrm{ml}$ and it was concluded that even the educated required awareness about the importance vitamin D [16]. Similar results are seen in our study ${ }_{2}$ the 25hydroxyvitamin $D$ levels ranged between 5.15 and $43.01 \mathrm{ng} / \mathrm{ml}$. Majority of the students $(89 \%)$ had deficient 25-hydroxyvitamin $D$ levels $(<20 \mathrm{ng} / \mathrm{ml})$ and $8 \%$ of the student had insufficient 25hydroxyvitamin D levels (21 to $30 \mathrm{ng} / \mathrm{ml}$ ) while only $3 \%$ of the students had sufficient 25hydroxyvitamin D levels (30 to $100 \mathrm{ng} / \mathrm{ml}$ ). The mean and median 25-hydroxyvitamin $D$ levels were $14.01 \pm 6.20 \mathrm{ng} / \mathrm{ml}$ and $12.95 \mathrm{ng} / \mathrm{ml}$ respectively indicating overall vitamin $D$ deficiency. These findings suggest that, there is high prevalence of vitamin $D$ deficiency in the study area to the extent that almost every individual is having either vitamin $D$ deficiency or insufficiency translating almost 9 out of 10 individuals with vitamin $\mathrm{D}$ deficiency.

In the present study, $54 \%$ of the students had history of use of sun tan in past 12 months. However, the vitamin D deficiency was noted in almost equal number of students with history of sun tanning $(90.74 \%)$ and those who did not have history of sun tanning $(86.96 \%) \quad(p=0.597)$ suggesting lack of association between history of sun tan and vitamin $D$ deficiency. These findings need further validation due to lack of similar data in the literature.

\section{Limitations}

The potential limitation of this study was that it was cross-sectional rather than longitudinal. Comparisons between first-year and fourth-year students became sub-optimal. Also, the chemiluminescence immunoassay is not the gold standard method for the measurement of $25(\mathrm{OH}) \mathrm{D}$ levels. Besides, information on consumption of milk and exposure to sunlight was collected by means of a validated questionnaire rather than data collection sheet. Dual-energy X-ray absorptiometry scan is suggested to evaluate bone mineral density which was not done for economic limitation.

\section{Conclusion}

The vitamin $D$ deficiency is highly prevalent in asymptomatic medical students residing in study area. The present study interestingly showed lack of relationship of vitamin $D$ deficiency with the welldefined risk factors in literature prompting to look for newer risk factors in this country. Further studies are required to confirm these findings and plan interventions to prevent Vitamin D deficiency in asymptomatic population.

\section{Acknowledgements: None}

\section{Conflict of interest: None}

\section{References}

1. Pfotenhauer KM, Shubrook JH. Vitamin D deficiency, its role in health and disease, and current supplementation recommendations. J Am Osteopath Assoc. 2017 May 1; 117(5):301-5. PMID: 28459478 DOI: 10.7556/jaoa.2017.055

2. Bouillon R, Carmeliet G, Verlinden L, van Etten E, Verstuyf A, Luderer HF, Lieben L, Mathieu C, Demay M. Vitamin D and human health: lessons from vitamin $D$ receptor null mice. Endocr Rev. 2008 Oct; 29(6):726-76. PMID: 18694980 DOI: 10.1210/er.2008-0004

3. Prentice A. Vitamin D deficiency: a global perspective. Nutr Rev. 2008 Oct; 66(10 Suppl 2):S153-64. PMID: 18844843 DOI: $10.1111 / \mathrm{j} .1753-4887.2008 .00100 . x$

4. Bolek-Berquist J, Elliott ME, Gangnon RE, Gemar D, Engelke J, Lawrence SJ, Hansen KE. Use of a questionnaire to assess vitamin $D$ status in young adults. Public Health Nutr. 2009 Feb; 12(2):236-43. PMID: 18752694 DOI: 10.1017/S136898000800356X

5. Wacker M, Holick MF. Sunlight and vitamin D: A global perspective for health. Dermatoendocrinol. 2013 Jan 1; 5(1): 51-108. PMID: 24494042 DOI: 10.4161/derm.24494

6. Pike JW, Christakos S. Biology and mechanisms of action of the vitamin D hormone. Endocrinol Metab Clin North Am. 2017 Dec; 46(4):815-43. PMID: 29080638 DOI: 10.1016/j.ecl.2017.07.001

7. van Schoor N, Lips P. Global overview of vitamin D status. Endocrinol Metab Clin North Am. 2017 Dec; 46(4):845-70. PMID: 29080639 DOI: 10.1016/j.ecl.2017.07.002

8. Forrest KY, Stuhldreher WL. Prevalence and correlates of vitamin D deficiency in US adults. Nutr Res. 2011 Jan; 31(1):48-54. $21310306 \quad$ PMID: 10.1016/j.nutres.2010.12.001

9. Arneson WL, Arneson DL. Current methods for routine clinical laboratory testing of vitamin D levels. Lab Med. 2013 Feb 1; 44(1):e38-e42. DOI: 10.1309/LMONQZQ27TIN7XFS

10. WHO Scientific Group on the Prevention and Management of Osteoporosis (2000: Geneva, Switzerland). Prevention and management of osteoporosis: report of a WHO scientific group. WHO Tech Rep Ser. 2003; 921:1-164. Available from http://www.who.int/iris/handle/10665/42841 (Last accessed February 17, 2018)

11. Bouillon R, van Schoor NM, Gielen E, Boonen S, Mathieu C, Vanderschueren D, Lips P. Optimal vitamin D status: a critical analysis on the basis of evidence-based medicine. $J$ Clin Endocrinol Metab. 2013 Aug; 98(8):E1283-304. PMID: 23922354 DOI: 10.1210/jc.2013-1195

12. Man RE, Li LJ, Cheng CY, Wong TY, Lamoureux E, Sabanayagam C. Prevalence and determinants of suboptimal vitamin $D$ levels in a multiethnic Asian population. Nutrients. 2017 Mar 22, 9(3):E313. PMID: 28327512 DOI: 10.3390/nu9030313

13. Babu US, Calvo MS. Modern India and the vitamin D dilemma: evidence for the need of a national food fortification program. Mol Nutr Food Res. 2010 Aug; 54(8):1134-47. PMID: 20440690 DOI: 10.1002/mnfr.200900480

14. Selvarajan S, Gunaseelan V, Anandabaskar N, Xavier AS, Srinivasamurthy S, Kamalanathan SK, Sahoo JP. Systematic review on vitamin $D$ level in apparently healthy Indian population and analysis of its associated factors. Indian J Endocrinol Metab. 2017 Sep-Oct; 21(5):765-75. PMID: 28989890 DOI: 10.4103/ijem.IJEM_168_17 
15. Sowah $D$, Fan $X$, Dennett $L$, Hagtvedt $R$, Straube $S$. Vitamin $D$ levels and deficiency with different occupations: a systematic review. BMC Public Health. 2017 Jun 22 17(1):519. PMID: 28637448 DOI: 10.1186/s12889-0174436-z
16. Zabihiyeganeh $M$, Jahed SA, Sarami S, Nojomi $M$. Hypovitaminosis D: are medical students at risk? Int J Prev Med. 2014 Sep; 5(9): 1161-8. PMID: 253173 